\title{
Studies on Carbon-Fly Ash Composites with Chopped PANOX Fibers
}

\author{
Rakesh V. Patel ${ }^{1}$ and S. Manocha ${ }^{2}$ \\ ${ }^{1}$ Center for Interdisciplinary Studies in Science and Technology (CISST), Sardar Patel University, Vallabh Vidyanagar 388 120, India \\ ${ }^{2}$ Department of Materials Science, Sardar Patel University, Vallabh Vidyanagar 388 120, India
}

Correspondence should be addressed to Rakesh V. Patel; drrvpatel@gmail.com

Received 13 August 2013; Revised 17 October 2013; Accepted 6 November 2013

Academic Editor: Masamichi Kawai

Copyright (C) 2013 R. V. Patel and S. Manocha. This is an open access article distributed under the Creative Commons Attribution License, which permits unrestricted use, distribution, and reproduction in any medium, provided the original work is properly cited.

Chemical analysis and morphological studies of fly ash reveals the complex chemical constituents present as spherical particles with diameter of less than $25 \mu \mathrm{m}$. The constituents of fly ash are silica, alumina, iron oxide, titanium dioxide, calcium and magnesium oxide, and other trace elements. The use of thermosetting as well thermoplastic polymer matrix has been made by several workers to develop polymer matrix fly ash particulate composites by using the hard and abrasive properties of fly ash and lightweight of polymers. Such composites have poor mechanical strength, fracture toughness, and thermal stability. To overcome these shortcomings, in carbonaceous matrix, the carbon fibers were added as additional reinforcement along with the fly ash. The composites were developed with two different methods known as Dry method and Wet method. The processing parameters such as temperature and pressure were optimized in establishing the carbon matrix. Physical, thermal, and mechanical characteristics were studied. The microstructures of composites show good compatibility between fly ash and fibers with the carbon matrix. These composites have higher strength, thermal stability, and toughness as compared to polymer matrix fly ash particulate composites.

\section{Introduction}

The spherical shaped materials blown out from the furnace during combustion of coal in thermal power stations make up $75 \%$ of ash generated. The spherules when empty are called cenospheres and when filled up with smaller spheres are known as plerospheres [1]. The cenospheres comprise of $0.5-1.0$ weight percentage of the fly ash individual particles are chemically fairly homogeneous, but the pronounced compositional variation exists among particles with similar physical and structural attributes [2]. Cenospheres are compressed of nearly stoichiometric mullite $\left(3 \mathrm{Al}_{2} \mathrm{O}_{3} \cdot 2 \mathrm{SiO}_{2}\right)$ needles bonded by aluminosilicate glass of similar composition that offers excellent thermal, elastic, and mechanical characteristics for use in thermostructural applications [3]. Elemental map study through energy filtered TEM shows the aluminosilicate-based and iron oxide based-nanoparticles are present in the fly ash [4]. Unburned organic matter during combustion of coal leaves carbon in three different forms in the fly ash $[5,6]$. Fly ash contains toxic elements like $\mathrm{Co}, \mathrm{Pb}$, $\mathrm{Ni}, \mathrm{Cd}, \mathrm{Cu}, \mathrm{Fe}$, and $\mathrm{Zn}$ in trace $[7,8]$.

Particle filled polymer composites have become attractive because of their wide applications and low cost. Polymers such as Nylon 6 [9], Natural Rubber [10, 11], Styrene Butadiene Rubber [10], Epoxy [11, 12], Poly styrene, Poly Aniline, and HDPE, incorporating inorganic mineral fillers into plastic resin, improve various physical properties of the materials such as mechanical strength, modulus, and heat distortion temperature as compared to neat resin components. In general, the mechanical properties of particulate filled composites depend strongly on size, shape, and distribution of filler particles in the matrix and good adhesion at the interface surface.

However, use of PMCs imposes some real constraints [13] on structural applications due to comparatively weak matrix, imbibe water, and other liquids to a significant degree cannot perform well at moderate elevated temperature, internal cracking is so common, higher thermal expansion, 
TABLE 1: Composition of Fly ash.

\begin{tabular}{lcccc}
\hline Sample & $\% \mathrm{SiO}_{2}$ & $\% \mathrm{Al}_{2} \mathrm{O}_{3}$ & $\% \mathrm{Fe}_{2} \mathrm{O}_{3}$ & \%Carbon \\
\hline Fly ash & 56.34 & 22.63 & 7.90 & 2.86 \\
\hline
\end{tabular}

maintaining good adhesion is difficult, chemical and thermal degradations in service often occurs.

The addition of short PANOX fibers matrix allows stress transfer across the matrix crack to improve toughness. Therefore, in the present work, the addition of fly ash to the carbonaceous precursor with the additional reinforcement carbonaceous/carbon fibers was carried out to fabricate composite. These composites were characterized and it was seen that the additional reinforcement with the fly ash as filler could improve the strength of the composites as compared to single reinforcement.

\section{Experimental}

2.1. Materials Used. Fly ash was obtained from thermal power plant, Ahmedabad with specific gravity 2.19, and its composition is given in Table 1. Particle size distribution given in Figure 1(a) shows the size of the particles is less than $25 \mu$. The SEM micrograph Figure 1(b) shows fly ash particle shape is mainly spherical.

Morphology most frequently seen is cenospheres others are the fragments and lumpish organic particles. Novolac type phenolic resin powder with hardener obtained from Gujarat Phenolic synthetics Pvt. Ltd. Baroda was used as carbon precursor. Short PANOX fibers and PAN-based carbon fibers used as reinforcement. Surface oxygen complexes of both types of fibers are given in Table 2.

2.2. Procedure. The raw materials, namely, fly ash, PANOX, and resin, were mixed via two routes, namely, dry powder method (pr) and wet solution method (sr).

2.2.1. Dry Method. In the dry route, milling of the raw materials was carried out for uniform mixing. Powder mixture was pressed in a die at 20-30 MPa pressure with temperature up to $150^{\circ} \mathrm{C}$. Rectangular green composite blocks of size $150 \times 30 \times$ 5-7 mm were prepared. These green composites samples were heat treated at $1000^{\circ} \mathrm{C}$ under inertatmosphere.

2.2.2. Wet Method. Fly ash and fibers were first mixed in the phenolic resin solution and stirred well till fibers were uniformly distributed in the solution. This mixture was oven dried at $60-65^{\circ} \mathrm{C}$. Rectangular green composite blocks of size $150 \times 30 \times 5-7 \mathrm{~mm}$ were prepared. These green composites samples were heat treated at $1000^{\circ} \mathrm{C}$ under inert atmosphere.

2.3. Characterization. Particle size analysis of the fly ash was carried out by using particle size analyzer (PSA2001) working on the principle of Stock's law of sedimentation under LASER light. The samples were characterized for their physical properties; for example, density and open porosity. Open porosity was determined using kerosene under vacuum at
TABLE 2: Surface oxygen complexes of the fibers.

\begin{tabular}{lccc}
\hline Sample & $-\mathrm{OH}$ & $-\mathrm{COOH}$ & Lactonic \\
\hline PANOX & 405 & 361 & 84 \\
C-Fibers & 60 & 57 & 60 \\
\hline
\end{tabular}

$\sim 0.01$ bar. Bulk densities were measured through dimension and mass $(\mathrm{m} / \mathrm{v})$. Optical microscopy of the composites were studied under the optical microscope (LABORLUX 12 POL S) after fine polishing with using alumina powder with particle size up to $0.05 \mu \mathrm{m}$. polished surface was observed for the distribution of fly ash particles and fibers in the Surface morphology of the composites were observed in Scanning Electron Microscope HITACHI S $3000 \mathrm{~N}$ after coating with conducting layer of Pt-Pd alloy through ion sputter (HITACHI E-1010). Thermal oxidation behavior of the composites in air was studied by TGA (Mettler TG50) and the coefficient of thermal expansion was measured using Mettler TA4000. Flexural strength was measured through Shimadzu AG-100kNG. Rockwell hardness of the composites was measured by digital Rockwell hardness tester TRSDM.

\section{Results and Discussion}

Physical characteristics of the composites prepared through solution route $(\mathrm{sr})$ and powder route (pr) heat-treated at $1000^{\circ} \mathrm{C}$ are shown in Figure 2.

It shows that the densities of the composites prepared through solution route are lower than that of dry powder method. Open porosity is higher than that of the composites made through powder route (pr). As the amount of phenolic resin increases, the density increases and open porosity decreases in both the cases. As the amount of fly ash is higher, it hinders the compaction during pressing; hence, it leave higher porosity.

Thermal behavior of the composites in air gives information about thermal oxidative stability of composites during high temperature applications. Figure 3 shows TGA curve of carbon/ceramic composites with and without fibrous reinforcement heat-treated at $1000^{\circ} \mathrm{C}$ for 1 hour. Most of the composites show the onset of weight loss at $450-600^{\circ} \mathrm{C}$ in air. Only single steep decrease in weight was observed in most of composites. Also composites made with fly ash show more thermal stability as compared to pure glassy carbon. Thus the addition of particulate reinforcement provides more interfacial bonding and more thermal stability (Table 3).

The optical micrograph (Figure 4(a)) shows the well distribution of the fly ash particles in the glassy carbon matrix. Optical activity was observed at the interface between fly ash particles and carbon matrix at $1000^{\circ} \mathrm{C}$. This reveals the presence of turbostratic carbon present at the interface due to shearing forces during the shrinkage of the matrix and also due to effect of the metal oxides present [14-16] in the fly ash particles. (Figure 4(b)), SEM micrograph of composites $\mathrm{HTT}$ at $1000^{\circ} \mathrm{C}$ at lower magnification shows well-established matrix and (Figure 4(c)) good sintering and well distribution of fly ash particles with glassy carbon matrix. Figure 4(d) shows nanoparticles of the size of $50-100 \mathrm{~nm}$ present on 


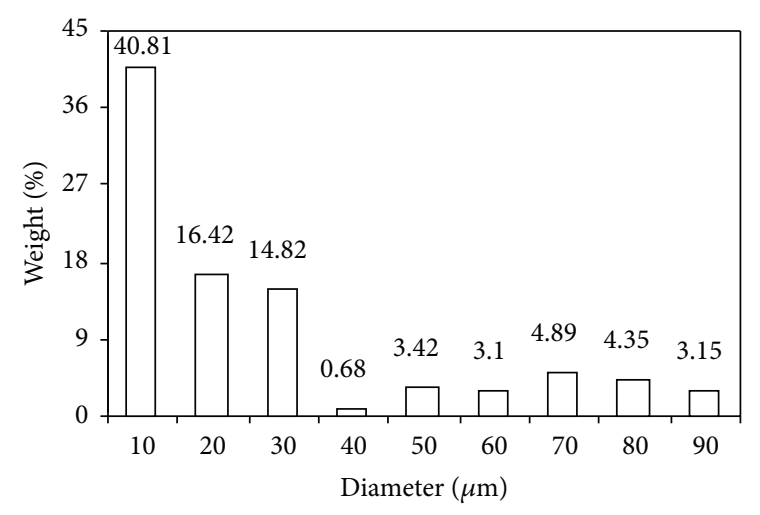

(a)

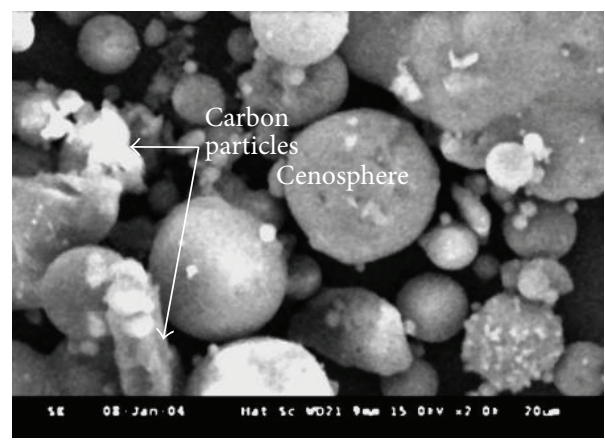

(b)

FIGURE 1: (a) Particle size distribution; (b) SEM of Fly ash particles distribution of Fly ash.

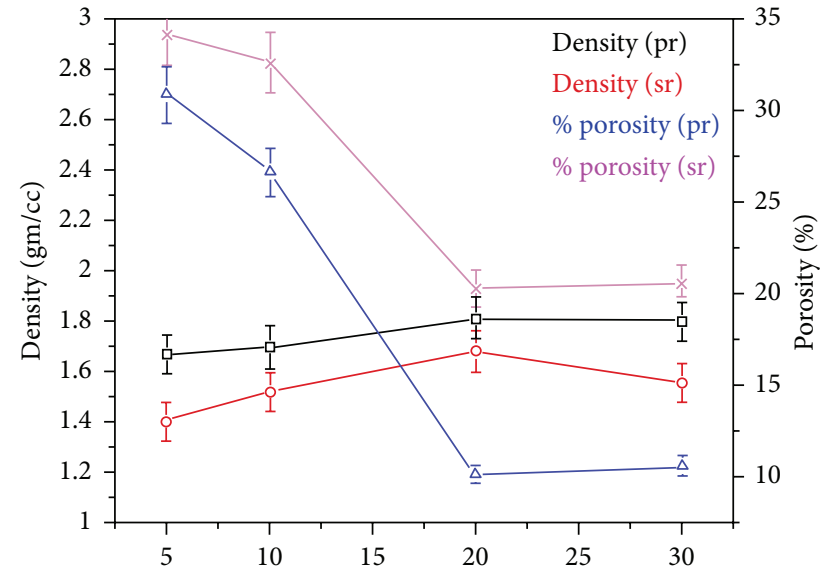

FIGURE 2: Physical properties of the composites made through solution route $(\mathrm{sr})$ and powder route $(\mathrm{pr})$ heat-treated at $1000^{\circ} \mathrm{C}$.

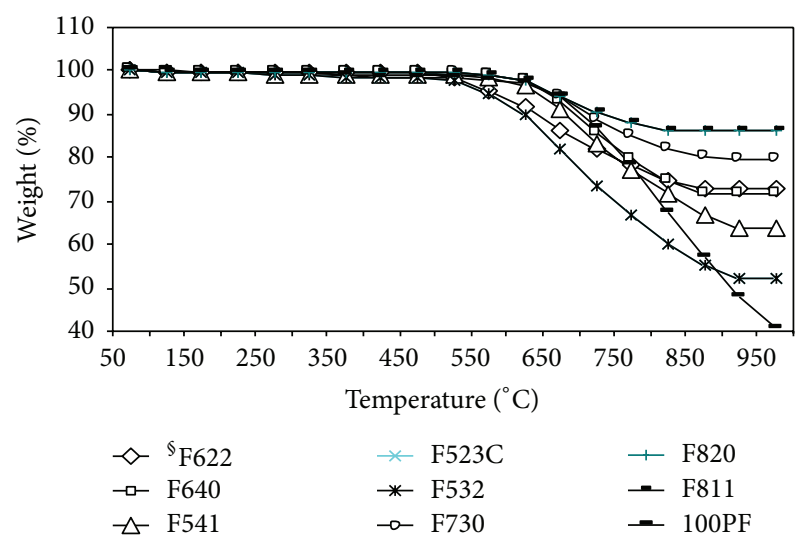

FIGURE 3: TGA curve of the composites heat-treated at $1000^{\circ} \mathrm{C}$ in air.

themicron size fly ash particle, which forms and protrudes out on the surface during heating [17]. Figure 4(e) shows the well interfacial bonding between the fiber and matrix without any crack because here matrix as well as fibers both
TABle 3: Description of composites.

\begin{tabular}{ll}
\hline Sample ID & Description (\% by weight) \\
\hline F910 & 90\% fly ash, 10\% PF Resin \\
F820 & 80\% fly ash, 20\% PF Resin \\
F811 & 80\% fly ash, 10\% PF Resin, 10\% PANOX fibers \\
F730 & 70\% fly ash, 30\% PF Resin \\
F640 & 60\% fly ash, 40\% PF Resin \\
F631 & 60\% fly ash, 30\% PF Resin, 10\% PANOX fibers \\
F622 & 60\% fly ash, 20\% PF Resin, 20\% PANOX fibers \\
F541 & 50\% fly ash, 40\% PF Resin, 10\% PANOX fibers \\
F522 & 50\% fly ash, 25\% PF Resin, 25\% PANOX fibers \\
F532 & 50\% fly ash, 30\% PF Resin, 20\% PANOX fibers \\
F423 & 40\% fly ash, 25\% PF Resin, 35\% PANOX fibers \\
F424 & 40\% fly ash, 20\% PF Resin, 40\% PANOX fibers \\
\hline
\end{tabular}

shrink together during heat-treatment and it also possess more surface functional groups compared to the carbon fiber as mentioned in Table 2, which helps in the strong bonding [17]. Composite with carbon fiber (Figure 4(f)) shows less bonding with matrix and shrinkage cracks are also seen in the matrix due to thermal stresses during heat-treatment.

Figure 5 shows the curve of coefficient of thermal expansion of various composites with and without fibers. Composite made with only fly ash shows higher expansion as compared to the composites made with fibers. As the amount of fly ash increases, thermal expansion increases. The constituents of the fly ash are oxide ceramics like $\mathrm{SiO}_{2}(\mathrm{CTE} 6.7 \times$ $\left.10^{-6} /{ }^{\circ} \mathrm{C}\right)$ and $\mathrm{Fe}_{2} \mathrm{O}_{3}\left(5.20 \times 10^{-6} /{ }^{\circ} \mathrm{C}\right)$, that is, which possess higher individual thermal expansion coefficient as compared to carbon. Chopped fibers are oriented in different directions. Therefore, the expansion in fiber dominated composites is slight low.

Flexural strength of the carbon-ceramic composites is shown in Figure 6. It is highly understandable that the high strength in the composite can be achieved by utilizing fiber strength in the composite. Therefore, stabilized PAN fibers are added in the composites to improve the strength and 


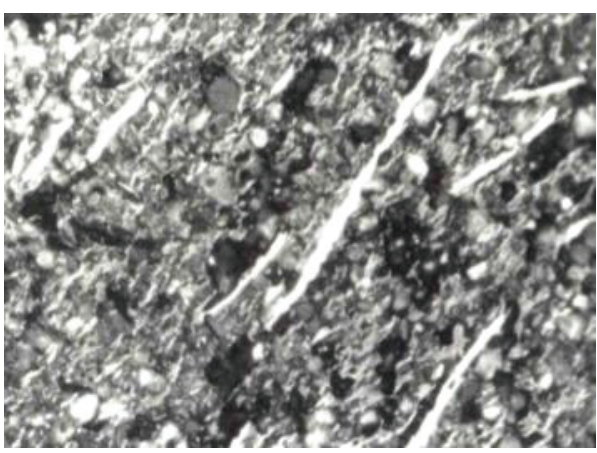

(a)

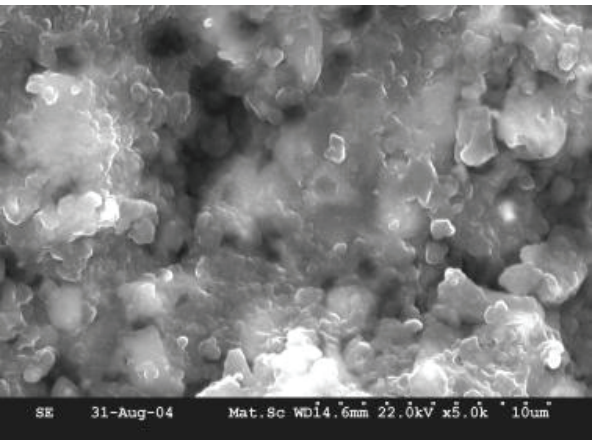

(c)

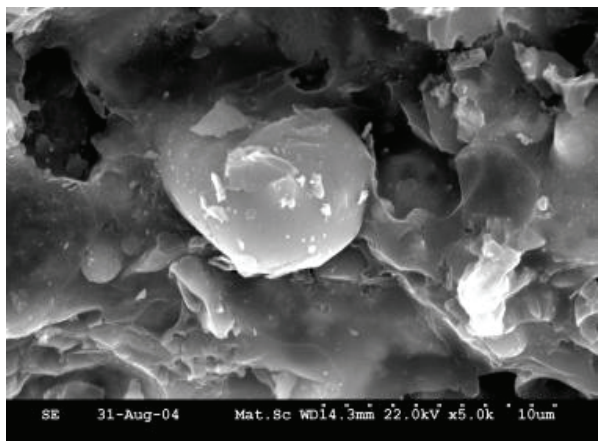

(e)

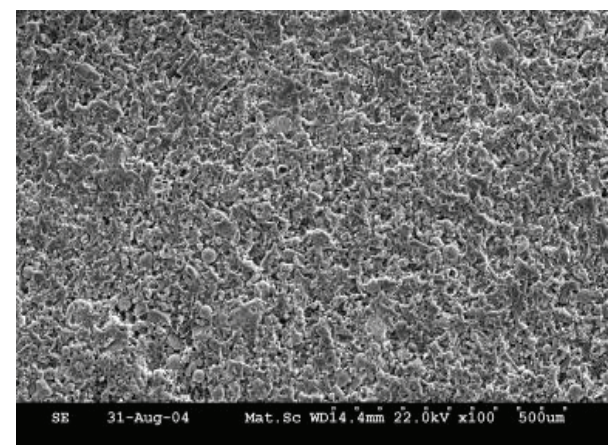

(b)

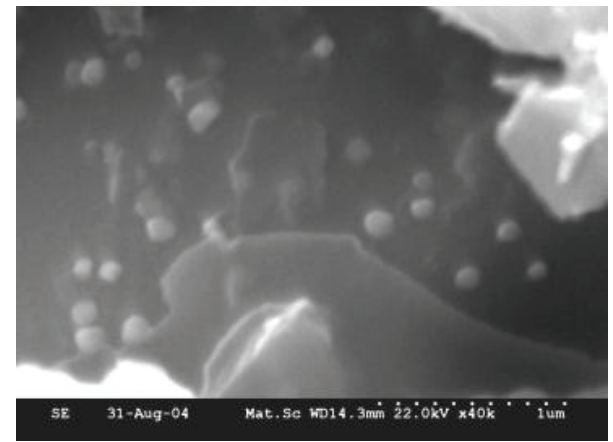

(d)

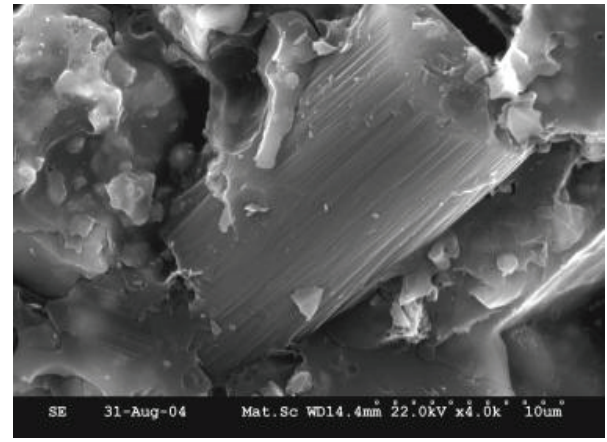

(f)

FIgURE 4: (a) Optical micrograph of the composite, (b) SEM Micrograph with magnification 100x, (c) SEM Micrograph with magnification 5000x, SEM micrograph of the composites (d) with nanoparticles (e) with PANOX fiber (f) with carbon fiber.

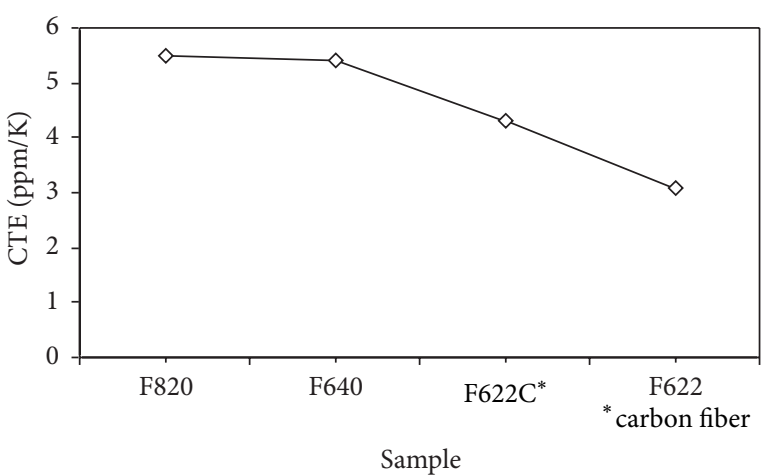

FIGURE 5: Coefficients of thermal expansion of the composites heattreated at $1000^{\circ} \mathrm{C}$. stiffness of carbon/ceramic composites. The fracture mode of the composites was brittle fracture. The figure represents that as the amount of the fiber increases the flexural strength of the composites increase and also as the amount of carbon matrix increases the flexural strength increases. In case of high fly ash composites the strength is low due to more porosity as shown in Figure 2.

The carbon/ceramic composites fabricated using fly ash only as reinforcement was analyzed for Rockwell hardness and results are shown in Table 4 . Rockwell hardness of carbon/ceramic composites depend on the bonding between matrix and the reinforcements. The composites containing only fly ash show the descending order in hardness value as the fly ash percentage increases from $40 \%$ to $90 \%$. The HRL values vary from 103.74 to 55.47 . This reveals the lesser 


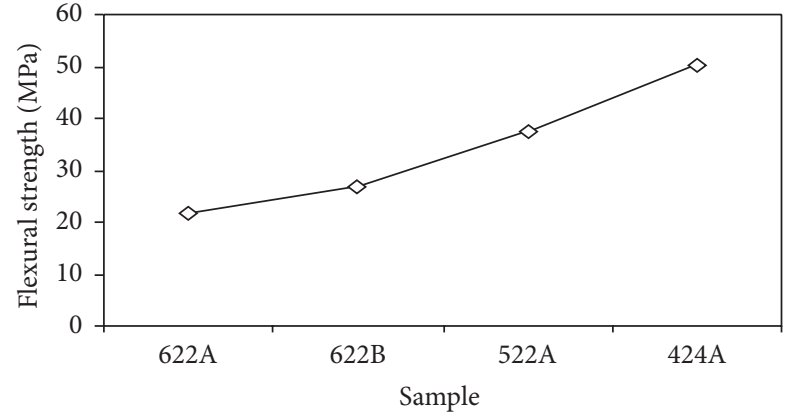

Figure 6: Flexural strength of the composites with various compositions.

TABLE 4: Rockwell hardness of the composites prepared without fibers.

\begin{tabular}{lcc}
\hline Sr. no. & Sample & Rockwell hardness (HRL) \\
\hline 1 & F910 & 55.47 \\
2 & F820 & 67.57 \\
3 & F730 & 113.27 \\
4 & F640 & 103.74 \\
\hline
\end{tabular}

TABLE 5: Rockwell hardness of the composites with fibers.

\begin{tabular}{lcc}
\hline Sr. no. & Sample & Rockwell hardness (HRL) \\
\hline 1 & F811 & 78.77 \\
2 & F721 & 115.47 \\
3 & F631 & 114.34 \\
4 & F622 & 101.38 \\
5 & F541 & 113.65 \\
6 & F532 & 116.27 \\
\hline
\end{tabular}

bonding between matrix and fly ash particles in case of high weight percentage of fly ash in composites. Table 5 shows the Rockwell hardness of composites made by using fly ash and fibers as reinforcements. This shows that the composites with fiber addition along with fly ash show more hardness.

\section{Conclusion}

Fly ash particles show good compatibility with the carbon matrix along with the fibers. Fly ash can be best utilized, with and without addition of carbonaceous fibers, as raw material for making carbon-ceramic composites for mechanical applications using powder compaction route. The addition of fibers improves the strength and toughness of the fabricated composites.

\section{References}

[1] K. C. Sahu, "Characterization and utilization of fly ash," in Fly Ash Utilization for Value Added Products, B. Chatterjee, K. K. Singh, and N. G. Goswami, Eds., pp. 15-22, NML, Jamshedpur, India, 1999.

[2] R. Gieré, L. E. Carleton, and G. R. Lumpkin, "Micro- and nanochemistry of fly ash from a coal-fired power plant," The American Mineralogist, vol. 88, no. 11-12, pp. 1853-1865, 2003.
[3] R. Melvin Gottschalk, R. John Hellmann, E. Barry Sheetz, L. Andre Boehman, and R. David Stettler, "Commercially useful byproducts of coal combustion," Ceramic Transactions, vol. 119, pp. 125-134, 2001.

[4] Y. Chen, N. Shah, F. E. Huggins, G. P. Huffman, and A. Dozier, "Characterization of ultrafine coal fly ash particles by energyfiltered TEM," Journal of Microscopy, vol. 217, no. 3, pp. 225-234, 2005.

[5] J. C. Hower, R. B. Rathbone, U. M. Graham et al., "Approaches to the petrographic characterization of fly ash," in Proceedings of the International Coal Testing Conference, pp. 49-54, Lexington, Ky, USA, May 1995.

[6] M. M. Maroto-Valer, D. N. Taulbee, and J. C. Hower, "A novel separation of the carbon types present in fly ash by density gradient centrifugation," in Proceedings of the Conference on Unburned Carbon on Utility Fly Ash, p. 49, University of Kentucky, Lexington, Ky, USA, 1998.

[7] A. G. Kim and G. Kazonich, "Mass release of trace elements from coal combustion by-products," in Proceedings of the International Ash Utilization Symposium, Center for Applied Energy Research, Lexington, Ky, USA, 1999.

[8] D. Tracy Branam, T. Ronald Smith, V. Margaret Ennis, and P. Jammes Rybarczysk, "Trace element partitioning in groundwater at an abandoned mine-land site reclaimed with coal combustion products," in Proceedings of the International Ash Utilization Symposium, Center for Applied Energy Research, Lexington, Ky, USA, 1999.

[9] S. Bose and P. A. Mahanwar, "Effect of titanate coupling agent on the mechanical, thermal, dielectric, rheological, and morphological properties of filled nylon 6," Journal of Minerals \& Materials Characterization \& Engineering, vol. 99, no. 1, pp. 266-272, 2006.

[10] N. Sombatsompop, S. Thongsang, T. Markpin, and E. Wimolmala, "Fly ash particles and precipitated silica as fillers in rubbers. I. Untreated fillers in natural rubber and styrenebutadiene rubber compounds," Journal of Applied Polymer Science, vol. 93, no. 5, pp. 2119-2130, 2004.

[11] K. Kishore, S. M. Kulkarni, S. Sharathchandra, and D. Sunil, "On the use of an instrumented set-up to characterize the impact behaviour of an epoxy system containing varying fly ash content," Polymer Testing, vol. 21, no. 7, pp. 763-771, 2002.

[12] K. Kishore, N. L. Ravikumar, and D. Sunil, "The effect of a starch envelope on fly ash particles on the impact properties of filled epoxy composites," Advanced Composites Letters, vol. 12, no. 2, pp. 45-54, 2003.

[13] F. J. Macgarry, "Polymer matrix composites," Annual Review of Materials Science, vol. 24, pp. 63-82, 1994.

[14] M. Inagaki, Y. Okada, H. Miura, and H. Konno, "Preparation of carbon-coated transition metal particles from mixtures of metal oxide and polyvinylchloride," Carbon, vol. 37, no. 2, pp. 329-334, 1999.

[15] M. Inagaki, K. Fujita, Y. Takeuchi, K. Oshida, H. Iwata, and H. Konno, "Formation of graphite crystals at 1000-1200॰C from mixtures of vinyl polymers with metal oxides," Carbon, vol. 39, no. 6, pp. 921-929, 2001.

[16] H. Kamiya, H. Yamada, M. Tukada, and M. Naito, "Analysis of Ash Adhesion Behavior at High Temperature Condition by Using Computer controlled FE-SEM with Heat Treatment Unit," http://www.netl.doe.gov/publications/ proceedings/02/GasCleaning.1lpaper.pdf. 
[17] R. K. Jain, L. M. Manocha, and O. P. Bahl, "Surface treatment of carbon fibres with nitric acid and its influence on the mechanical behaviour of composites made with phenolic and furan (resins) as matrices," Indian Journal of Technology, vol. 29, no. 4, pp. 163-172, 1991. 

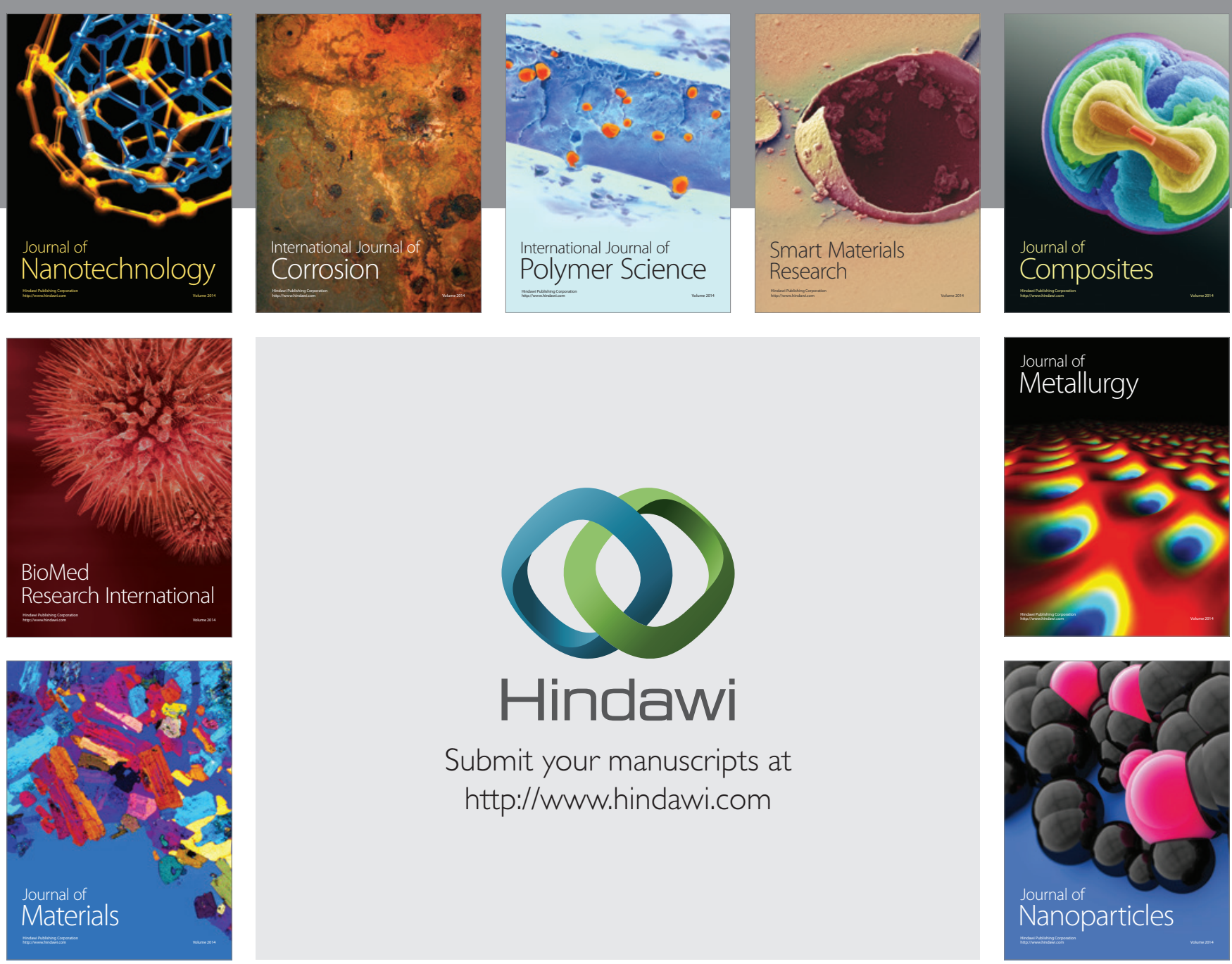

Submit your manuscripts at http://www.hindawi.com
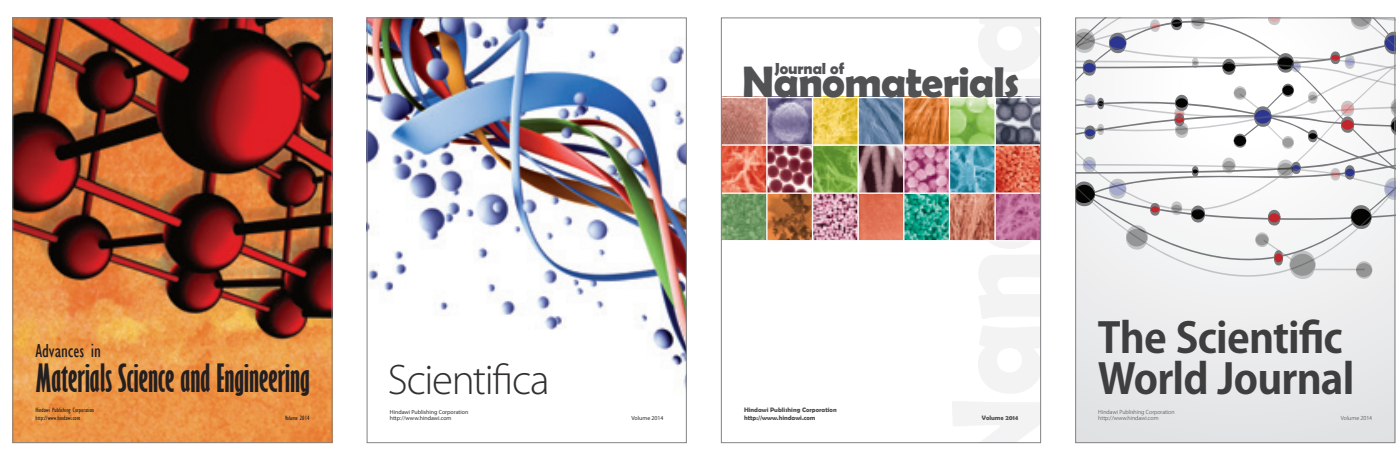

\section{The Scientific World Journal}
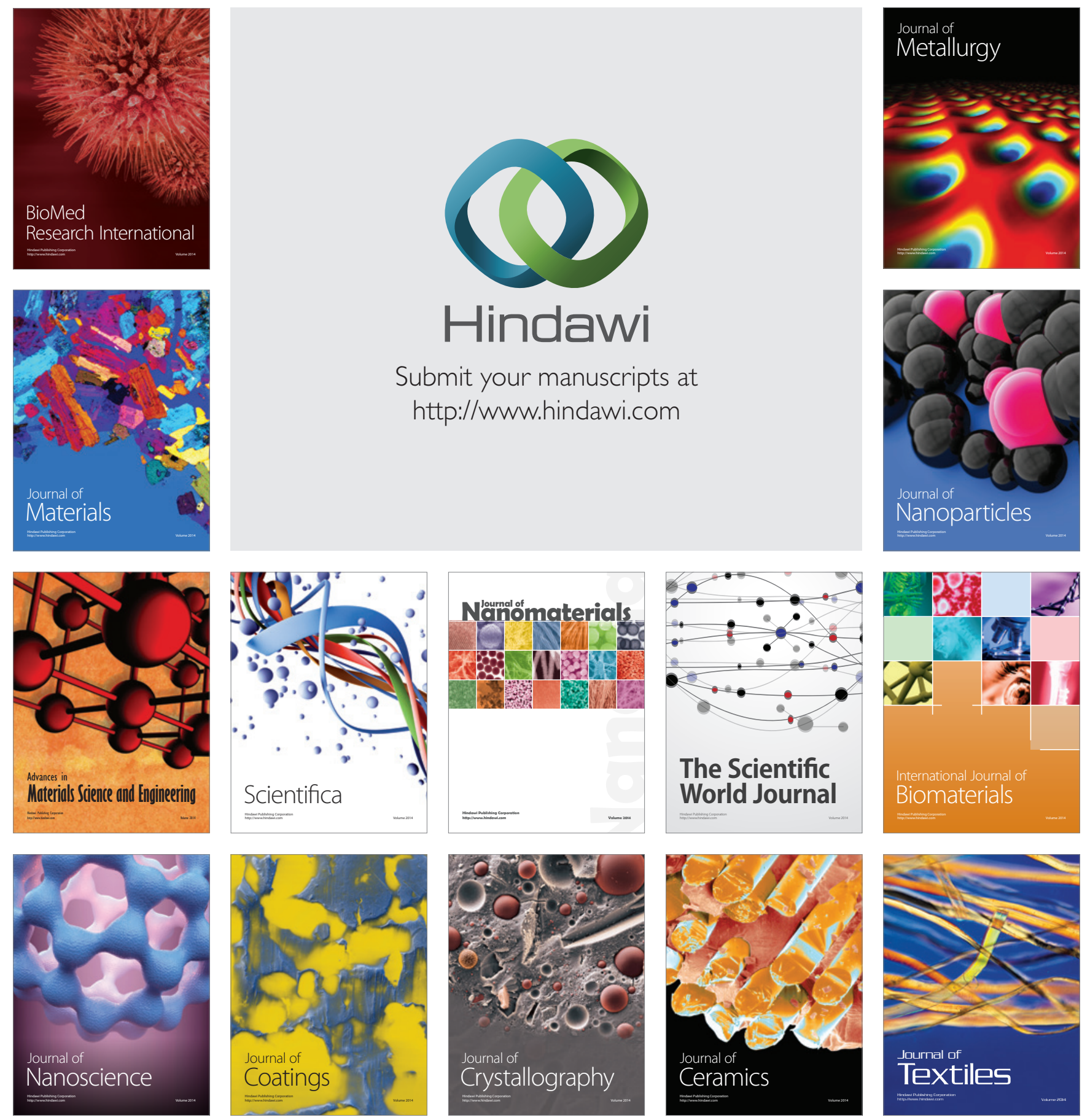